\title{
Predictors of premature termination from psychotherapy for anorexia nervosa: Low treatment credibility, early therapy alliance, and self-transcendence
}

\author{
Jennifer Jordan, PhD1,2 (D) | Virginia V. W. Mclntosh, PhD | \\ Frances A. Carter, PhD ${ }^{2}$ | Peter R. Joyce, MD, PhD, DSC, FRSNZ, FRANZCP ${ }^{1}$ | \\ Christopher M. A. Frampton, PhD ${ }^{1}$ | Suzanne E. Luty, BM, BS, PhD, FRANZCP1 | \\ Janice M. McKenzie, MB, ChB, FRANZCP1 ｜ Janet D. Carter, PhD ${ }^{3}$ | \\ Cynthia M. Bulik, PhD 4,5
}

${ }^{1}$ Department of Psychological Medicine, University of Otago, Christchurch, New Zealand

${ }^{2}$ Canterbury District Health Board, Christchurch, New Zealand

${ }^{3}$ Department of Psychology, University of Canterbury, Christchurch, New Zealand

${ }^{4}$ Departments of Psychiatry and Nutrition, University of North Carolina at Chapel Hill, North Carolina 27599-7160

${ }^{5}$ Department of Medical Epidemiology and Biostatistics, Karolinska Institutet, Stockholm, Sweden

Correspondence Jennifer Jordan, PhD, Department of Psychological Medicine, University of Otago, Christchurch, PO Box 4345, Christchurch 8140, New Zealand. Email: jenny.jordan@otago.ac.nz

Funding information Health Research Council of New Zealand, Grant/Award Number: 97/144

\begin{abstract}
Objective: Failure to complete treatment for anorexia nervosa (AN) is- common, clinically concerning but difficult to predict. This study examines whether therapy-related factors (patient-rated pretreatment credibility and early therapeutic alliance) predict subsequent premature termination of treatment (PTT) alongside self-transcendence (a previously identified clinical predictor) in women with AN.

Methods: 56 women aged 17-40 years participating in a randomized outpatient psychotherapy trial for AN. Treatment completion was defined as attending 15/20 planned sessions. Measures were the Treatment Credibility, Temperament and Character Inventory, Vanderbilt Therapeutic Alliance Scale and the Vanderbilt Psychotherapy Process Scale. Statistics were univariate tests, correlations, and logistic regression.

Results: Treatment credibility and certain early patient and therapist alliance/process subscales predicted PTT. Lower self-transcendence and lower early process accounted for $33 \%$ of the variance in predicting PTT.

Discussion: Routine assessment of treatment credibility and early process (comprehensively assessed from multiple perspectives) may help clinicians reduce PTT thereby enhancing treatment outcomes.
\end{abstract}

KEYWORDS

anorexia nervosa, drop out, premature termination, self-transcendence, therapy alliance, treatment credibility

Retention in treatment for anorexia nervosa (AN) offers the best chance of achieving symptom improvement yet premature termination of treatment (PTT) is common, with $30-40 \%$ of adult outpatients failing to complete psychotherapy (DeJong, Broadbent, \& Schmidt, 2012). This is a significant concern for those affected, families and services, given serious morbidity and elevated mortality in AN (see Elbaky, Hay, Le Grange, Lacey, Crosby, \& Touyz, 2014). Much research on PTT focuses on pretreatment patient clinical characteristics however significant methodological issues including inconsistent definitions of PTT, differing measures, timing of assessments, and sample characteristics have led to conflicting results and non-replication (Fassino, Piero, Tomba, \& Abbate-Daga, 2009; Jordan et al. 2014). Attention has now turned to potentially potent transdiagnostic therapy-related common factors influencing PTT, including patient treatment credibility beliefs 
and the quality and process of the therapeutic relationship itself (Sly, 2009).

Research on therapeutic alliance in outpatient treatment for AN has been hampered because relatively few treatment trials in adults measure process-related factors (Brauhardt, de Zwaan, \& Hilbert, 2014; Zaitsoff, Pullmer, Cyr, \& Aime, 2015). Studies of family therapy for adolescent AN highlight that timing (early, middle, or late stage) and perspective (adolescent, parent, therapist, or observer) yield different findings regarding alliance; however, high parental alliance reliably predicts treatment completion (Zaitsoff, Pullmer, Cyr, \& Aime, 2015). In adults, higher early therapy alliance was associated with reduced PTT in one study(Sly, Morgan, Mountford, \& Lacey, 2013), however, another reported early positive alliance did not predict PTT or weight gain - conversely, early weight gain predicted later positive alliance (Brown, Mountford, \& Waller, 2013). Patient treatment credibility ratings have received relatively little attention in predicting PTT in AN, although lack of congruence between patient and therapist expectations of treatment predicted dropout in those with eating disorders (Clinton, 1996).

The need for further process-outcome (including PTT) research in eating disorders has been noted (Zaitsoff et al., 2015), however it is important that identified clinical predictors are examined in relation to process variables, preferably within the same samples to advance understanding of the relative strength, and treatment implications, of these associations.

Our previous study examining clinical predictors found low selftranscendence was associated with PTT, whereas demographic, eating disorder severity, AN subtype, and Axis I comorbidity variable were not (Jordan et al., 2014).

In this study, we hypothesize that low patient-rated treatment credibility and low early therapeutic alliance will predict subsequent PTT in our AN psychotherapy trial. We then examine the relative contribution of these therapy-related predictors with our previously identified clinical predictor (self-transcendence) in predicting PTT within the same sample.

\section{1 | METHODS}

\section{1 | Participants}

Participants were 56 women aged $17-40$ years with spectrum AN (strict AN, BMI 14.5-17.5; and Lenient AN, BMI 17.6 < 19) presenting to a randomized outpatient psychotherapy trial (Mclntosh et al., 2005). All had DSM-IV psychological features of AN. Amenorrhea was not required. The Southern Regional Health Authority Ethics Committee (Canterbury) provided ethical approval. Specialist Supportive Clinical Management (SSCM) was superior to Interpersonal Psychotherapy (IPT) in intention to treat analyses and to IPT and Cognitive Behavior Therapy (CBT) in completer analyses (McIntosh et al., 2005).

\section{2 | Procedure}

\subsection{1 | Treatment completion definition}

PTT was defined as a premature end to planned treatment, whether client-initiated, staff-initiated or due to logistic reasons (Sly, 2009) as reasons for PTT (below) were varied, PTT timing was steady (mean 8.1, range 1-14 sessions), and subgroup numbers (including for PTT timing) were too small for meaningful analyses.

Treatment completion [Completers group ( $n=35,62.5 \%) ;$ PTT group ( $n=21,37.5 \%)]$ was defined a priori as completing 15 or more of 20 (75\%) scheduled sessions. PTT reasons (DeJong, Broadbent, \& Schmidt, 2012) included: staff-initiated clinical withdrawals due to deterioration (medical, $n=3,5.4 \%$; psychiatric, $n=1,1.8 \%$ ); patientinitiated withdrawal ( $n=10,17.9 \%$ ); logistical withdrawal [moved city $(n=3,5.4 \%)$ and progress withdrawal (early improvers who discontinued, $n=4,7.1 \%)]$.

\section{3 | Measures}

\subsubsection{Treatment credibility scale}

This three question scale, self-rated after session one used a 6-point Likert-type scale: How logical does the treatment seem? How applicable to your problems does treatment seem? How helpful do you think treatment will be? (Morrison \& Shapiro, 1987).

\subsubsection{Temperament and character inventory}

The TCl has 293 yes/no items (Cloninger, Svrakic, \& Przybeck, 1991). The self-transcendence scale (51 items) comprises five facets: (a) creative self-forgetfulness versus self-consciousness; (b) transpersonal identification versus self-isolation; (c) spiritual acceptance versus rational materialism; (d) enlightened versus objective; (e) idealistic versus practical.

\subsection{3 | Vanderbilt Therapeutic Alliance Scale-revised (VTAS-R)}

The VTAS-R is a 37 item observer rating scale comprising therapist, patient, and therapist + patient together subscales (Krupnick, Sotsky, Watkins, Eklin, \& Pilkonis, 1996).

\subsubsection{Vanderbilt Psychotherapy Process Scale (VPPS)}

The VPPS is a 90-item observer rating scale with eight subscales: patient participation, negative therapist attitudes, patient exploration, patient psychic distress, therapist warmth and friendliness, patient hostility, therapist exploration and patient dependence (O'Malley, Suh, \& Strupp, 1983).

\subsection{Rating of therapy alliance}

Raters were graduate clinical psychology students or clinical psychologists unaware of therapy randomization. Early phase sessions (sessions 1-5) were used. Inter-rater reliability checks were conducted on 25/ 156 sessions (16\%) for the VTAS and 40/156 (26\%) for the VPPS. Intra-class correlations for both the VTAS-R and VPPS subscales indicated moderate reliability (Table 1). The coefficient of variation (variation between raters relative to the overall mean for each subscale) was satisfactory for VTAS-R subscales and acceptable to satisfactory for the VPPS. 
TABLE 1 Inter-rater reliability of tape ratings in the therapy alliance scales

\begin{tabular}{|lll|}
\hline Measure/subscales & $\begin{array}{l}\text { Intraclass } \\
\text { correlations }\end{array}$ & $\begin{array}{l}\text { Coefficients } \\
\text { of variation }\end{array}$ \\
\hline $\begin{array}{l}\text { Vanderbilt therapeutic alliance scale (VTAS-R) } \\
\text { Therapist }\end{array}$ & .66 & $6.6 \%$ \\
Patient & .78 & $7.7 \%$ \\
Therapist + patient & .78 & $8.6 \%$ \\
$\quad$ together & & \\
Vanderbilt psychotherapy process scale (VPPS) & \\
Patient participation & .74 & $10.7 \%$ \\
Patient exploration & .65 & $13.0 \%$ \\
Patient psychic distress & .65 & $7.1 \%$ \\
Negative therapist attitudes & .85 & $9.1 \%$ \\
Patient hostility & .67 & $3.6 \%$ \\
Therapist warmth & .26 & $16.0 \%$ \\
Therapist exploration & .39 & $11.9 \%$ \\
Patient dependence & .43 & $6.1 \%$. \\
\hline
\end{tabular}

Note. Inter-rater reliability checks were conducted on 25/156 sessions (16\%) for the VTAS and 40/156 (26\%) for the VPPS.

antraclass correlations (two way mixed effects model).

${ }^{b}$ The coefficient of variation (variation between raters relative to the overall mean for each subscale).

\section{5 | Statistical analyses}

The Statistical Package for the Social Sciences (version 23) was used to analyze data. Statistics included student t-tests, Pearson's correlations, odd ratios, and Cohen's $d$ effect sizes. Sequential binary logistic regression analyses identified the strongest alliance/process predictor among those statistically significant in univariate analyses. The relative contribution of the strongest alliance/process predictor was examined then in relation to treatment credibility and to self-transcendence in logistic regression models. The $p$ values was .05 with no correction for multiple comparisons.

\section{2 | RESULTS}

There were no statistically significant differences across therapies in the rate of PTT: SSCM 28.6\%, CBT 38.9\% and IPT 42.9\%, $X^{2}(2,56)=$ $0.75, p=.69$. Odds ratios and confidence intervals $(\mathrm{Cl})$ for 2-way comparisons between therapies were $\mathrm{SSCM}$ versus $\mathrm{CBT}$, OR $=1.59(\mathrm{Cl}$ $0.36,7.12)$; SSCM versus IPT, $\mathrm{OR}=1.88(\mathrm{Cl} 0.44,7.96)$; $\mathrm{CBT}$ versus IPT, OR $=1.12$ (Cl 0.33, 4.25).

Table 2 presents univariate and logistic regression analyses of early variables potentially associated with PTT.

Total credibility predicted PTT. VTAS-R early phase total mean (SD) score was 4.17 (0.26). Low scores on VTAS-R patient, and VPPS patient exploration, therapist exploration, and therapist warmth subscales predicted PTT. Patient exploration was the strongest alliance/ process predictor in logistic regression so was used to represent therapy alliance in subsequent analyses. VTAS and VPPS totals were highly correlated (.64). Correlations were small for ST-VTAS .16, ST-VPPS -.02 and ST-credibility 21.

Sub-analyses of the self-transcendence subscale indicated statistically significant differences on two of the five facets: facet 4: enlight- ened versus objective [Completers $M=5.06(S D=3.51)$ versus PTT $M=2.93(S D=2.34, t=2.09, p<.05)]$ and facet 5 : idealistic versus practical [Completers $M=5.17(S D=1.99)$ versus $\mathrm{PTT} M=3.64$ (SD $=1.78, t=2.50, p<.05)$ (Jordan et al., 2014).

VTAS and VPPS totals were highly correlated (.64). Correlations were small for ST-VTAS .16, ST-VPPS -.02 and ST-credibility.21.

Binary logistic regression models established the relative contributions of key variables associated with PTT. The best model accounted for $33 \%$ of the variance in predicting PTT, with both selftranscendence and patient exploration remaining in the model. In each pairwise regression, all variables remained in the model, indicating that patient exploration, treatment credibility and self-transcendence all make independent contributions to PTT.

In post hoc exploratory analyses examining whether varying the definitions for PTT affected these results, the pattern of key findings remained (Supporting Information Table S1 available from the corresponding author).

\section{3 | DISCUSSION}

As hypothesized, low scores for treatment credibility and (some) early therapeutic alliance/process subscales were associated with PTT. Treatment credibility, patient exploration, and self-transcendence all made independent contributions in predicting PTT. Mean alliance levels in this study benchmark favorably with the original VTAS-R paper, and the variance accounted for by these therapy-process variables in the models is consistent with other psychotherapy research (Horvath, Re, Fluckiger, \& Symonds, 2011).

Our finding of low patient alliance predicting PTT is consistent with Sly, Morgan, Mountford, \& Lacey (2013) but not Brown, Mountford, \& Waller, (2013). It aligns with previous research regarding the predictive power of patient alliance (see Horvath, Re, Fluckiger, \& Symonds, 2011) and mounting evidence suggesting that regular monitoring of client progress and response to session content improves outcomes (see Dyer, Hooke, \& Page, 2014; Peterson, Becker, Treasure, Shafran, \& Bryant-Waugh, 2016). Several VPPS therapist subscales also predicted PTT, highlighting therapist contribution to the alliance/ process and countering previous reports that only patient perspectives were informative (see Del Re, Flückiger, Horvath, Symonds, \& Wampold, 2012).

Findings from the AN family therapy literature noted earlier, and variability across our measures suggest that alliance/process should be comprehensively assessed (whose perspective, how and when measured) to deepen understanding of nuances in the relationship between alliance/process and outcomes including PTT (Crits-Christoph, Gibbons, \& Mukherjee, 2013; Zaitsoff et al., 2015).Variability in alliance levels across studies may account for conflicting results therefore benchmarking levels of alliance is important (DeRubeis, Gelfand, German, Fournier, \& Forand, 2014). That alliance did not predict PTT in the Brown et al. study may relate to their consistently high levels of alliance (Brown et al., 2013). Low treatment credibility also predicted late dropout from web-based CBT for eating disorders (ter Huurne, Postel, 
TABLE 2 Association of key variables assessed early in therapy to subsequent PTT

\begin{tabular}{|c|c|c|c|c|c|c|}
\hline Variables & $\begin{array}{l}\text { Completed } \\
\text { Mean (SD) }\end{array}$ & $\begin{array}{l}\text { PTT } \\
\text { Mean (SD) }\end{array}$ & $t$ & $p$ & \multicolumn{2}{|c|}{ Effect size $^{b}$} \\
\hline \multicolumn{7}{|l|}{ Treatment credibility ratings $^{c}$} \\
\hline & $n=35$ & $n=21$ & & & \multirow{2}{*}{\multicolumn{2}{|c|}{$0.69(0.12-1.23)$}} \\
\hline Total credibility & $12.90(2.07)$ & $11.38(2.44)$ & 2.49 & .02 & & \\
\hline \multicolumn{7}{|c|}{ Vanderbilt Therapeutic Alliance Scale - Early phase ${ }^{d}$} \\
\hline & $n=31$ & $n=19$ & & & \multirow{4}{*}{\multicolumn{2}{|c|}{$\begin{array}{l}-0.27(-0.84-0.31 \\
0.67(0.08-1.25) \\
0.44(-0.15-1.01)\end{array}$}} \\
\hline Therapist subscale & $55.51(2.55)$ & $56.32(3.58)$ & -.94 & .35 & & \\
\hline Patient subscale & $48.03(4.15)$ & $45.37(4.30)$ & 2.12 & .03 & & \\
\hline Therapist \& Patient subscale & $52.03(4.56)$ & $50.00(4.78)$ & 1.52 & .14 & & \\
\hline \multicolumn{7}{|c|}{ Vanderbilt Psychotherapy Process Scale - Early phase } \\
\hline & $n=33$ & $n=20$ & & & \multirow{8}{*}{\multicolumn{2}{|c|}{$\begin{array}{l}0.40(-0.17-0.95) \\
0.00(-0.56-0.56) \\
0.73(0.15-1.29) \\
0.10(-0.45-0.66) \\
0.09(-0.46-0.65) \\
0.71(0.13-1.27) \\
0.71(0.13-1.27)\end{array}$}} \\
\hline Patient participation & $4.06(0.77)$ & $3.72(0.98)$ & 1.40 & .17 & & \\
\hline Negative therapist attitude & $1.01(0.04)$ & $1.01(0.04)$ & .16 & .87 & & \\
\hline Patient exploration & $2.98(0.57)$ & $2.56(0.58)$ & 2.62 & .01 & & \\
\hline Patient psychic distress & $2.06(0.40)$ & $2.02(0.37)$ & .40 & .69 & & \\
\hline Patient hostility & $1.10(0.22)$ & $1.08(0.20)$ & .21 & .84 & & \\
\hline Therapist warmth & $3.65(0.53)$ & $3.27(0.55)$ & 2.51 & .02 & & \\
\hline Therapist exploration & $2.82(0.29)$ & $2.59(0.37)$ & 2.51 & .02 & & \\
\hline \multicolumn{2}{|l|}{ Logistic regression model $^{e}$} & \multicolumn{2}{|l|}{ Odds ratio } & $95 \% \mathrm{Cl}$ & Wald & $p$ \\
\hline \multicolumn{7}{|c|}{ Self-transcendence vs. Treatment credibility (total) } \\
\hline \multicolumn{7}{|c|}{$\begin{array}{l}\text { Model Nagelkerke } R^{2}=.29 \text {, cases correctly classified } 72.7 \% \\
\text { Variables remaining in the model }\end{array}$} \\
\hline \multicolumn{2}{|l|}{ Self-transcendence } & \multicolumn{2}{|l|}{0.92} & $0.85-0.99$ & \multirow{2}{*}{$\begin{array}{l}5.35 \\
5.35\end{array}$} & .02 \\
\hline \multicolumn{2}{|l|}{ Treatment credibility (total) } & 0.75 & \multicolumn{2}{|r|}{$0.57-1.00$} & & .05 \\
\hline \multicolumn{7}{|c|}{ Self-transcendence vs. Patient Exploration ${ }^{f}$} \\
\hline \multicolumn{7}{|c|}{$\begin{array}{l}\text { Model Nagelkerke } R^{2}=.33 \text {, cases correctly classified } 71.2 \% \\
\text { Variables remaining in the model }\end{array}$} \\
\hline \multicolumn{2}{|l|}{ Patient Exploration } & 0.27 & \multicolumn{2}{|r|}{$0.08-0.94$} & 4.26 & .04 \\
\hline \multicolumn{2}{|l|}{ Self-transcendence } & 0.91 & \multicolumn{2}{|r|}{$0.85-0.98$} & 6.25 & .01 \\
\hline \multicolumn{7}{|c|}{ Treatment credibility (total) vs. Patient Exploration } \\
\hline \multicolumn{7}{|c|}{$\begin{array}{l}\text { Model: Nagelkerke } R^{2}=.29 \text {, cases correctly classified } 75.5 \% \\
\text { Variables remaining in the model }\end{array}$} \\
\hline Patient Exploration & & 0.25 & & $0.07-0.85$ & 4.96 & .03 \\
\hline Treatment credibility (total) & & 0.72 & & $0.54-0.96$ & 5.06 & .03 \\
\hline
\end{tabular}

${ }^{a}$ Completer status is defined as completing 15 of 20 planned sessions. The PTT group includes those who completed $<15$ sessions for whatever reason.

${ }^{\mathrm{b}}$ Cohen's $d$.

${ }^{\mathrm{c}}$ Total credibility is the sum of Logical, Applicable, and Helpful subscales.

${ }^{\mathrm{d}}$ Early phase is sessions $1-5$.

e Logistic regression stepwise (forward conditional procedure). Degrees of freedom $=1$.

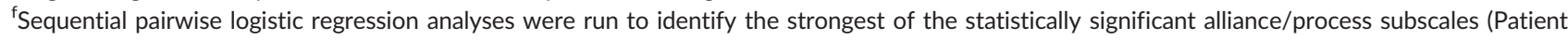
Exploration, Therapist Warmth and Therapist Exploration). VPPS Patient exploration as the strongest variable was then used to represent alliance/process in the logistic regression models with treatment credibility and self-transcendence.

de Haan, van der Palen, \& DeJong, 2017). The importance of considering patient preferences in AN therapies has been highlighted, notwithstanding that non-negotiable elements of evidenced-based treatments (e.g., weight-gain focus) may not be preferred (Peterson, Becker, Treasure, Shafran, \& Bryant-Waugh, 2016).

A statistically significant association of self-transcendence with PTT has been reported in only one other study (Pham-Scottez et al., 2012) although the direction of effect is unclear from that report. Self-consciousness, impatience, and concreteness characteristics of low self-transcendence have clear relevance to credibility and alliance beliefs.
Study limitations include that the PTT definition (including all reasons for noncompletion) risked obscuring differences through increased heterogeneity. Post-hoc analyses however confirmed that the pattern of findings remained regardless of definition, supporting use of this broad PTT definition. Study strengths include use of established alliance measures, independent blinded raters, and inter-rater reliability data.

Monitoring treatment credibility and early alliance/process will increase clinician awareness of PTT risk, enabling intervention to redress these issues to enhance retention and outcomes for AN. The finding of low self-transcendence predicting PTT requires replication. 


\section{ACKNOWLEDGMENTS}

This work was supported by project (Grant No. 97/144) and program grants from the Health Research Council of New Zealand. The authors thank Andrea Bartram, Leslie Livingston, Sarah Rowe, and Robyn Abbott for their assistance with these studies.

\section{CONFLICT OF INTEREST}

C.M.B. is a consultant for and grant recipient from Shire Pharmaceuticals.

\section{REFERENCES}

Brauhardt, A., de Zwaan, M., \& Hilbert, A. (2014). The therapeutic process in psychological treatments for eating disorders: A systematic review. International Journal of Eating Disorders, 47(6), 565-584. doi: 10.1002/eat.22287

Brown, A., Mountford, V. A., \& Waller, G. (2013). Is the therapeutic alliance overvalued in the treatment of eating disorders? International Journal of Eating Disorders, 46(8), 779-782. doi:10.1002/ eat.22177

Clinton, D. N. (1996). Why do eating disorder patients drop out? Psychotherapy and Psychosomatics, 65(1), 29-35. doi:10.1159/000289028

Cloninger, C. R., Svrakic, D. M., \& Przybeck, T. R. (1991). The Tridimensional Personality Questionnaire: US normative data. Psychological Reports, 69, 1047-1057. doi:10.2466/pr0.1991.69.3.1047

Crits-Christoph, P., Gibbons, M. C., \& Mukherjee, D. (2013). Psychotherapy process-outcome research. In M. J. Lambert (Ed.), Bergin and Garfield's handbook of psychotherapy and behavior change (Vol. 6, pp. 298-340). Hoboken, NJ: Wiley.

DeJong, H., Broadbent, H., \& Schmidt, U. (2012). A systematic review of dropout from treatment in outpatients with anorexia nervosa. International Journal of Eating Disorders, 45(5), 635-647. doi:10.1002/ eat.20956

Del Re, A. C., Flückiger, C., Horvath, A. O., Symonds, D., \& Wampold, B. E. (2012). Therapist effects in the therapeutic alliance-outcome relationship: A restricted-maximum likelihood meta-analysis. Clinical Psychology Review, 32(7), 642-649. doi:10.1016/j.cpr.2012.07.002

DeRubeis, R. J., Gelfand, L. A., German, R. E., Fournier, J. C., \& Forand, N. R. (2014). Understanding processes of change: How some patients reveal more than others-and some groups of therapists less-about what matters in psychotherapy. Psychotherapy Research, 24(3), 419428. doi:10.1080/10503307.2013.838654

Dyer, K., Hooke, G. R., \& Page, A. C. (2014). Effects of providing domain specific progress monitoring and feedback to therapists and patients on outcome. Psychotherapy Research, 26(3), 297-306. doi:10.1080/ 10503307.2014.983207

Elbaky, G., Hay, P., Le Grange, D., Lacey, H., Crosby, R., \& Touyz, S. (2014). Pre-treatment predictors of attrition in a randomised controlled trial of psychological therapy for severe and enduring anorexia nervosa. BMC Psychiatry, 14(1), 69. doi:10.1186/1471-244X-14-69

Fassino, S., Piero, A., Tomba, E., \& Abbate-Daga, G. (2009). Factors associated with dropout from treatment for eating disorders: A comprehensive literature review. BMC Psychiatry, 9, 67. doi:10.1186/1471244X-9-67

Horvath, A. O., Re, A. C. D., Fluckiger, C., \& Symonds, D. (2011). Alliance in individual psychotherapy Psychotherapy relationships that work: Evidence-based responsiveness (2nd ed., pp. 25-69). New York, NY: Oxford University Press.
Jordan, J., McIntosh, V. V. W., Carter, F. A., Joyce, P. R., Frampton, C. M. A., Luty, S. E., ... Bulik, C. M. (2014). Clinical characteristics associated with premature termination from outpatient psychotherapy for anorexia nervosa. European Eating Disorders Review, 22(4), 278-284. doi:10.1002/erv.2296

Krupnick, J. L., Sotsky, S. M., Watkins, J., Eklin, I., \& Pilkonis, P. A. (1996). The role of the therapeutic alliance in psychotherapy and pharmacotherapy outcome: findings in the National Institue of Mental Health Treatment of Depression Collaborative Research Program. Journal of Consulting and Clinical Psychology, 64, 532-539. doi:10. 1037/0022-006X.64.3.532

McIntosh, V. V., Jordan, J., Carter, F. A., Luty, S. E., McKenzie, J. M., Bulik, C. M., ... Joyce, P. R. (2005). Three psychotherapies for anorexia nervosa: A randomized controlled trial. American Journal of Psychiatry, 162, 741-747. doi:10.1176/appi.ajp.162.4.741

Morrison, L., \& Shapiro, D. (1987). Expectancies and outcomes in prescriptive vs. exploratory psychotherapy. British Journal of Clinical Psychology, 26, 59-60. doi:10.1111/j.2044-8260.1987.tb00724.x

O'Malley, S., Suh, C., \& Strupp, H. (1983). The Vanderbilt Psychotherapy Process Scale: A report on the scale development and a processoutcome study. Journal of Consulting and Clinical Psychology, 51(4), 581-586. doi:10.1037/0022-006X.51.4.581

Peterson, C. B., Becker, C. B., Treasure, J., Shafran, R., \& Bryant-Waugh, R. (2016). The three-legged stool of evidence-based practice in eating disorder treatment: research, clinical, and patient perspectives. BMC Medicine, 14(1), 69. doi:10.1186/s12916-016-0615-5

Pham-Scottez, A., Huas, C., Perez-Diaz, F., Nordon, C., Divac, S., Dardennes, R., ... Rouillon, F. (2012). Why do people with eating disorders drop out from inpatient treatment? The Role of Personality Factors. Journal of Nervous \& Mental Disease, 200(9), 807-813. doi: 10.1097/NMD.0b013e318266bbba

Sly, R. (2009). What's in a name? Classifying 'the dropout' from treatment for anorexia nervosa. European Eating Disorders Review: The Journal of the Eating Disorders Association, 17(6), 405-407. doi: 10.1002/erv.964

Sly, R., Morgan, J. F., Mountford, V. A., \& Lacey, J. H. (2013). Predicting premature termination of hospitalised treatment for anorexia nervosa: The roles of therapeutic alliance, motivation, and behaviour change. Eating Behavior, 14(2), 119-123. https://doi.org/10.1016/j. eatbeh.2013.01.007

ter Huurne, E. D., Postel, M. G., de Haan, H. A., van der Palen, J., \& DeJong, C. A. (2017). Treatment dropout in web-based cognitive behavioral therapy for patients with eating disorders. Psychiatric Research, 247, 182-193. doi:10.1016/j.psychres.2016.11.034

Zaitsoff, S., Pullmer, R., Cyr, M., \& Aime, H. (2015). The role of the therapeutic alliance in eating disorder treatment outcomes: A systematic review. Eating Disorders, 23(2), 99-114. doi:10.1080/10640266.2014.964623

\section{SUPPORTING INFORMATION}

Additional Supporting Information may be found online in the supporting information tab for this article.

How to cite this article: Jordan J, Mclntosh VVW, Carter FA, et al. Predictors of premature termination from psychotherapy for anorexia nervosa: Low treatment credibility, early therapy alliance, and self-transcendence. Int J Eat Disord. 2017;50:979983. https://doi.org/10.1002/eat.22726 